\title{
ESTABLISHING CONTROL ON CONSUMABLES INVENTORY IN A PRESSURE VESSEL MANUFACTURING INDUSTRY USING MICROSOFT EXCEL (A CASE STUDY)
}

\author{
Vignesh Ravichandran $^{1}$, N.Ganesh Kumar ${ }^{2}$ \\ ${ }^{1}$ UG Scholar, Dept. of Mechanical Engineering, PSG College of Technology, Coimbatore \\ ${ }^{2}$ Assistant Professor (SG), Dept. of Mechanical Engineering, PSG College of Technology, Coimbatore
}

\begin{abstract}
This paper is based on a case study in an air compressor manufacturing facility. This case study was conducted at the pressure vessel division. The pressure vessel division manufactures air receivers and air-oil separators for storing the compressed air. The facility neither had a proper model of inventory nor a replenishment policy with respect to the consumables inventory. Also there was no proper system in place to track the on-hand inventory. All the consumables were treated alike and there was not any discrimination between them. A proper model of inventory has been suggested after classifying the consumables suitably. Also a simple method to track the inventory has been proposed using an excel spreadsheet.
\end{abstract}

Keywords — consumables inventory; inventory classification; inventory models; inventory replenishment; controlling consumables inventory; microsoft excel;

\section{INTRODUCTION}

Consumables inventory are those kind of inventory which do not appear in the Bill Of Material (BOM). The consumables inventory is generally not brought into the BOM due to the nature of such items. For example, consider steel shots that are used in shot blasting, which is a consumable inventory. The steel shots cannot be specified in the BOM as to how many of them should be used for shot blasting a pressure vessel. Whereas consider the flanges, which is a direct material inventory, that can be specified in the BOM as to how many flanges need to be fitted to the tank. As this is the nature of the consumables inventory, a suitable method has to be followed to control the use and replenish such items. The cost of such items is a major factor, which determines the inventory policy to be followed. But it is not the only criteria on which the inventory policy is framed.

\section{LITERATURE REVIEW}

\subsection{Inventory Management}

The purpose of inventory is singular and simple, inventory is held to protect the sales [1]. A study that examines inventory management and the role it plays inimproving customer satisfaction is discussed in [2].Inventory control systems play a crucial role in enhancing effectiveness and efficiency in handling inventory of business firms [3]. The principal goal of inventorymanagement involves having to balance theconflicting economics of not wanting to hold toomuch stock [4]. The primary objectives of inventory management are:
- To minimize the possibility of disruption in the production schedule of a firm for want of raw material, stock and spares.

- To keep down capital investment in inventories.

There are various methods of analysis available namely [5],

- $\mathrm{ABC}$ analysis

- FSN analysis

- VED analysis

- XYZ analysis

- HML analysis

- SDE analysis

- GOLF analysis

- SOS analysis

Of the listed types, VED analysis was the most appropriate choice for this facility.

\subsection{VED Analysis}

VED stands for Vital, Essential, and Desirable Analysis. The classification is based on the criticality of the inventories [5].

- Vital (V): The materials that are critically needed for the running of the production line, which must be available in the facility all the times.

- Essential (E): The materials with lower critical need, which may be available in the facility. Essential items (E) are the items whose shortage or non-availability can only be afforded for a short time.

- Desirable (D): The remaining materials with lowest critically, the absence of which will not be detrimental. 


\section{ANALYSIS OF THE INVENTORY PROBLEM}

The inventory policy that was followed at the facility is that whenever the consumables run out-of-stock in the plant floor, the productions depart raises an indent with the materials department. The quantity that is required is specified in the indent and the materials department purchases the quantity required and hands them over to the productions department, thereby closing the indent. At the end of every month, the materials department takes stock of the inventory. The issued quantity is subtracted from the purchased quantity to obtain the on-hand inventory and the rest of the quantity was assumed consumed in the plant floor. This was the inventory policy that was followed for all the consumables, from costly NC thinner used to mix with paints to cheap waste clothes used for cleaning. Hence the objective of this study was to classify the inventory, set up a replenishment policy and a method to track the inventory.

\section{INVENTORY MODEL}

The inventory control technique proposed for the consumable items is the VED analysis technique. VED analysis is suitable to this facility because ensuring material availability is the prime objective of this study. The production line has stopped due to non-availability of consumables inventory. VED was preferred over $\mathrm{ABC}$ analysis because; a low cost item may be vital for the production process to take place. Hence VED analysis was performed to classify the consumables inventory. Ensuring availability of ' $\mathrm{V}$ ' and ' $\mathrm{E}$ ' items is important for the production process to take place uninterrupted.

\subsection{Minimum Order Quantity}

The consumable items are directly bought from suppliers who quote the cheapest price while ensuring the quality. In such cases, the supplier will be willing to supply the items only if a minimum quantity is ordered each time, which is known as the minimum order quantity. In all the cases, the required inventory or the demand for the consumable items was less than the minimum order quantity. The minimum order quantity may or may not be equal to the Economic Order Quantity. The EOQ was not determined due to certain constraints, as the primary objective was to ensure material availability.

\subsection{Inventory Policy for Vital Items}

Ensuring the material availability of vital items is very much essential for the production line to run continuously. Hence a suitable inventory model has been proposed which ensures the availability of vital items in the store at all times. The inventory model suggested is the classic EOQ model with the EOQ replaced by MOQ. The demand is constant and the lead times are known for all the suppliers. Required inventory, safety stock and re order level are calculated using equations (1), (2) and (3).

Minimum required inventory $=$ lead time demand + safety stock
Safety stock $=$ lead time variation $*$ demand

$$
\text { Re Order Level }=\text { Safety Stock }+ \text { Lead Time Demand }
$$

The re order level determines when to order and when the inventory level reaches the re order level, the quantity to be ordered is the minimum order quantity, although the required inventory is less than the minimum order quantity. In order to gauge against the uncertainties and to ensure material availability at all times, safety stock has been provided for vital items. The diagrammatic representation is given in figure 1.

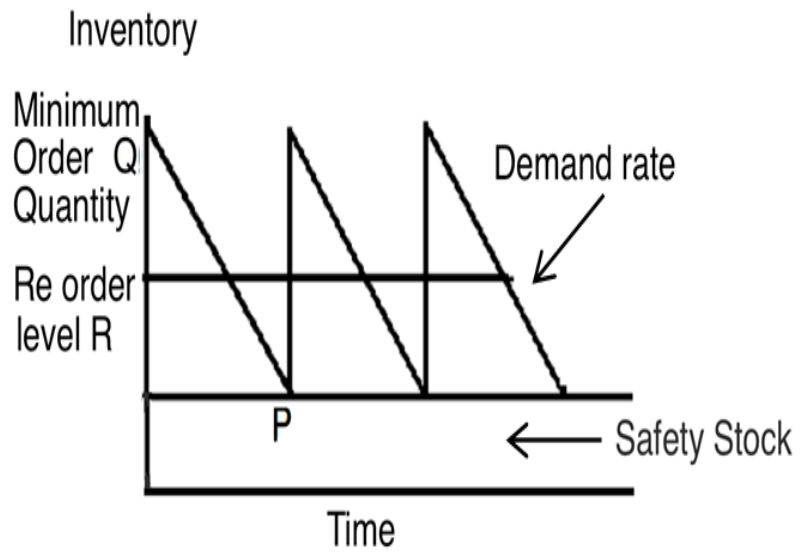

Fig.1 Inventory model for vital items

\subsection{Inventory Policy for Essential Items}

Essential items are those whose non-availability does not stop the production process as that of vital items but ensuring their availability is very much essential for the smooth operation of the production line. For example, the shop floor operator will be able to handle the hot tanks without gloves only for a short period of time. If the gloves are not available for a significant amount of time, the production line may stop. Therefore, ensuring the availability of essential items is also important though not as important as that of vital items. Therefore the inventory model suggested for essential items does not include safety stock. The model is represented diagrammatically in figure 2. Re order level is calculated using equation (3). When the inventory level reaches the re order level, minimum order quantity is ordered.

\subsection{Inventory Policy for Desirable Items}

The non-availability of desirable items does not stop the production process. These are items, which are required to carry out the production process as prescribed by the standard work. For instance, consider a dummy part, which is used to cover the hole in the pressure vessel before the painting process. The painting process could be done without using the dummy. Hence such items are classified as desirable items. The inventory model suggested for such items is that no inventory shall be maintained in the store for such desirable items. When the need for such items arises, an indent needs to be raised by the production department 
and the materials department will purchase the items and is handed over to the productions department. Figure 3 shows the composition of the consumables inventory at the facility.

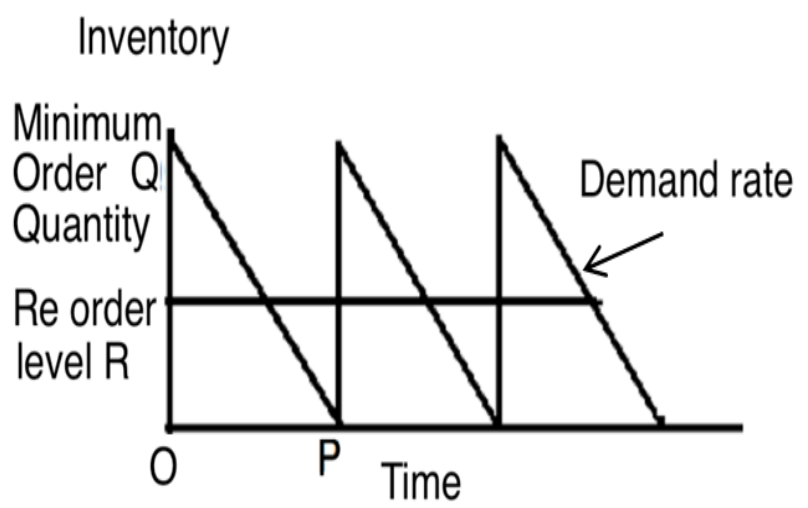

Fig 2 Inventory model for essential items

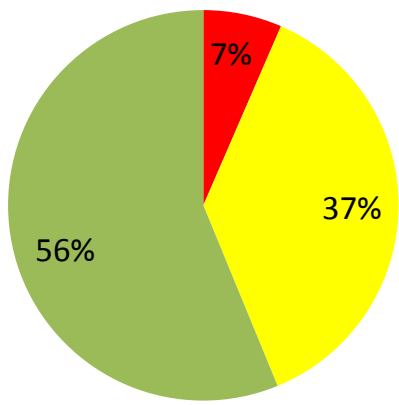

Total number of consumables $=176$ items

- VITAL ESSENTIAL DESIRABLE

Fig 3 Composition of consumables inventory

\section{TRACKING THE CONSUMABLES INVENTORY}

Currently, there is no proper control in issuing the consumable items to the shop floor. For example, the goggles used for protecting eyes while grinding is a consumable item. Although a goggle may last for a week, the grinder might consume more than one in a week due to his lethargy. In order to have a control on this, a material issue slip has been introduced in which the shop floor employees need to obtain the consent from their department for getting any consumable inventory from the stores. This will help in controlling the wastage of consumable inventory. Figure 4 shows a sample material issue slip that needs to be filled by the shop floor employee.

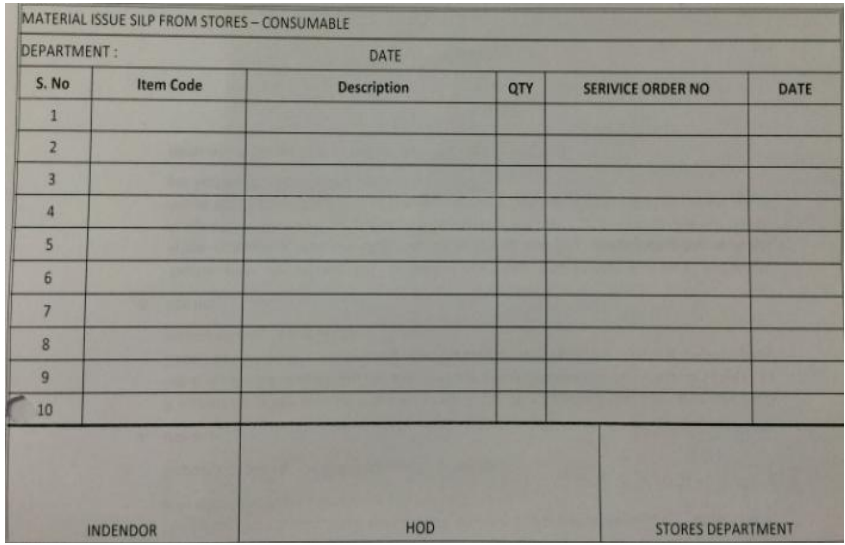

Fig 4 Sample material issue slip

\subsection{Using Microsoft Excel to Track Inventory}

An excel file has been created and given to the store to track the consumable inventory. The store in-charge has to update only two columns namely the receipt and issue columns. The receipt column represents the inventory received from the supplier and the issue column represents the quantity issued to the shop floor after the receipt of the material issue slip. The excel file has been to programmed to automatically compute the present stock (difference between receipt and issue).When the present stock level is greater than the reorder level, the present stock cell will be in green color, which indicates that the level is safe. When the present stock level is between the reorder level and the safety stock level, the color changes to yellow, cautioning the store in-charge. When the stock level falls below safety stock level, the color changes to red, indicating emergency condition. When the receipt and issue quantities are entered, the file automatically reveals the number of safe, caution and emergency items, based on which action needs to be taken accordingly. A pivot table with slicer and a pivot chart has been created to visualize the number of parts in safe, caution and emergency graphically. When the slicer button is hit, the corresponding data is displayed in the table. A dashboard has also been created which displays the status of any selecteditem from the dropdown list. Thus this excel file needs to be updated every day to exert control on the consumable inventory. This file also helps in tracking the status of various consumable items. Figure5 shows the dashboard and figure6 shows the pivot chart

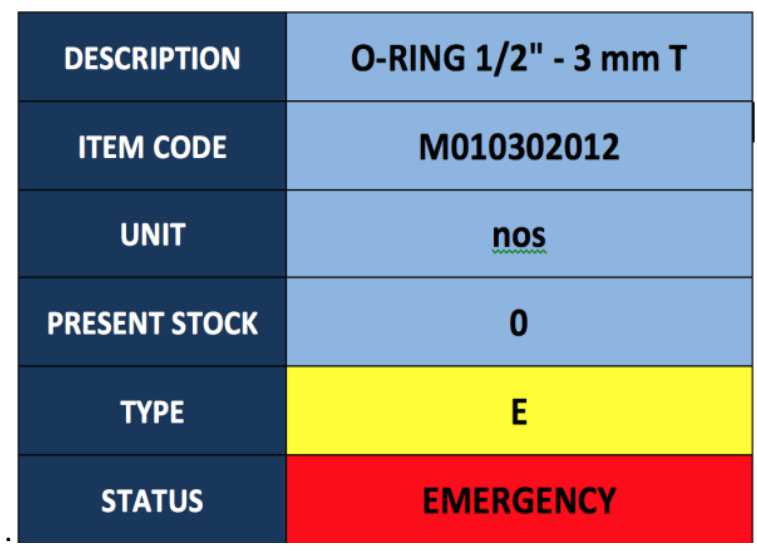

Fig 5 Dashboard 


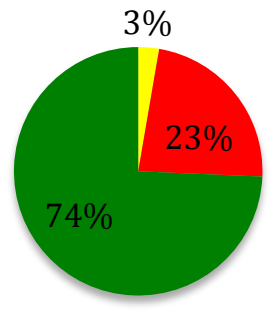

CAUTION $\square$ EMERGENCY $\square$ SAFE

\section{RESULTS}

Table 1 shows the majordifferences prior to and after implementing the inventory model, replenishment policy and the tracking system. This has ensured raw material availability and hence prevents production line stoppages that were occurring prior to implementation due to nonavailability of inventory. The classification has helped the materials department to discriminate between the various items. Following separate model will also cut down on the inventory costs and also establish greater control on them.

Fig 6 Pivot chart showing the inventory status

Table 1 Advantages of tracking consumables inventory

\begin{tabular}{|c|c|}
\hline Before implementation (Dec'14 - Jan'15) & After implementation (Feb - Mar '15) \\
\hline No classification of consumable inventory. & $\begin{array}{l}\text { Inventory classified as vital essential and desirable } \\
\text { items. }\end{array}$ \\
\hline for all items. & $\begin{array}{l}\text { Close monitoring for vital and essential items } \\
\text { established. }\end{array}$ \\
\hline $\begin{array}{l}\text { No proper inventory model for consumable inventory } \\
\text { replenishment. }\end{array}$ & $\begin{array}{l}\text { Fixed ordering system implemented; reorder levels } \\
\text { fixed for vital and essential items. }\end{array}$ \\
\hline $\begin{array}{l}\text { No control in issuing consumables to shop floor } \\
\text { employees. }\end{array}$ & $\begin{array}{l}\text { Material issue slip needs to be submitted to the store } \\
\text { to obtain the required inventory. }\end{array}$ \\
\hline Stock closing at the end of every month. & $\begin{array}{l}\text { Stock updated every day in an excel file that is } \\
\text { programmed to reveal the status of consumable } \\
\text { inventory as safe, caution or emergency. }\end{array}$ \\
\hline $\begin{array}{l}\text { sed for the purchase of all kinds } \\
\text { ory. }\end{array}$ & Indent needs to be raised only for desirable inventory. \\
\hline $\begin{array}{l}\text { All the items purchased and handed over to the shop } \\
\text { floor. }\end{array}$ & $\begin{array}{l}\text { Responsibility fixed at the store for issuing the items } \\
\text { on presentation of the material issue slip signed by } \\
\text { the productions head. }\end{array}$ \\
\hline Did not ensure material ava & Material availability ensured. \\
\hline
\end{tabular}

\section{CONCLUSION}

This case study has demonstrated how to establish control over the consumables inventory with specific reference to the pressure vessel manufacturing facility. In many cases, the consumables inventory may not be very closely monitored and the facilities tend to dump consumables inventory. Even if they are monitored, the consumption inside the plant floor is difficult to control unless stringent policies are formulated in issuing them to the employees in the shop floor. The methods proposed and implemented in this case study has helped the pressure vessel division effectively manage its consumables inventory by ensuring its availability and also ensuring that the right amount of inventory is maintained. It is essential that the consumables be classified in any of the methods mentioned in the literature, as treating all the items alike may not be a wise decision. This case study has also demonstrated how Microsoft excel can be effectively used to monitor the status of on-hand inventory in the store. Using an excel spreadsheet, the store in -charge can easily update the materials department on the status of the inventory as the excel sheet is programmed appropriately. Using excel is also cost effective. Hence establishing a proper replenishment policy has ensured the availability of consumables inventory and has eliminated the production line stoppages that were occurring due to the non-availability of consumables inventory. The procured items are now tracked effectively using Microsoft excel. The use of material issue slip has established accountability at the level of the shop floor employee.

\section{REFERENCES}

[1] Wilson, L. "How to Implement Lean Manufacturing". New York: McGraw-Hill Professional Publishing; 2009.

[2] Scott Grant Eckert, 2007, "Inventory Management and Its Effects on Customer Satisfaction," Journal of Business and Public Policy (ISSN: 1936-9794) volume 1, number 3.

[3] Kennedy Maeba, Dr. Margaret OlokoJomo, Dr. Walter Okibo, 2013, "Effect Of Inventory Control Systems On Operational Performance Of Tea Processing Firms: A Case Study Of Gianchore Tea Factory, Nyamira County, Kenya," The International Journal Of Business \& Management (ISSN 2321 8916), volume 1 , issue 5 . 
[4] S. L. Adeyemi and A. O. Salami, 2010, "Inventory Management: A Tool of Optimizing Resources in a Manufacturing Industry A Case Study of Coca-Cola Bottling Company, Ilorin Plant," Journal of Social Sciences, volume 23(2), pp. 135-142.

[5] D.Chandra Bose, "Inventory Management," New Delhi: Prentice Hall of India Pvt Ltd; 2006. 